\title{
Hannah Arendt: el delito original de los Estados Unidos Hannah Arendt and the United States Original Crime
}

\author{
Alfonso Ballesteros \\ Área de Filosofía del Derecho \\ Universidad de A Coruña
}

Fecha de recepción: 29/09/2915 | De aceptación: 30/05/2016 | De publicación: 22/06/2016

\section{RESUMEN}

Hannah Arendt aborda el problema del racismo contra la población negra en los Estados Unidos en el ámbito social y en el político, dos esferas de la vida humana que distingue cuidadosamente. Esta doble perspectiva ofrece un perfil completo de lo que denomina el "delito original" de los Estados Unidos: la esclavitud y la exclusión del pueblo negro e indio de la Constitución de 1787. Sus reflexiones sobre la educación pública segregada y sobre la desobediencia civil entre la población negra constituyen una oportunidad de repensar el problema de la inclusión jurídica en el mundo actual.

\section{PALABRAS CLAVE}

delito original, ciudadanía, racismo, minorías, constitución, derecho a tener derechos

\section{ABSTRACT}

Hannah Arendt addresses the problem of racism against African-Americans in the social and in the political realm. She makes a careful distinction between these two realms and this double perspective provides a complete profile of what she calls the "original crime" of the United States: Black slavery and the exclusion of Black and Indian people of the 1787 Constitution. His reflections on segregated public education and civil disobedience among African-Americans are an opportunity to rethink the problem of legal inclusion today.

\section{KEY WORDS}

Original Crime, Citizenship, Racism, Minorities, Constitution, Right to Have Rights 
Cuadernos Electrónicos de Filosofía del Derecho

Sumario: 1.- Las consecuencias de la esclavitud racial. 2.- La controversia sobre la educación pública segregada en Little Rock. 3.- La exclusión constitucional de la población negra de la ciudadanía y sus consecuencias. 4.La aceptación de la Constitución como condición para la ciudadanía y como reglas de juego en el ámbito público.

5.- Conclusiones.

1. Las consecuencias de la esclavitud racial

El "delito original" (original crime) ${ }^{1}$ es el término que Hannah Arendt acuña para hacer referencia a la esclavitud del pueblo afroamericano en los Estados Unidos y a la perpetuación de sus consecuencias mediante la legislación racial $^{2}$. En otro contexto la autora emplea este mismo término para referirse a la exclusión de la población negra e india del pacto constitucional de los Estados Unidos que en 1787 fundaba la nueva comunidad política ${ }^{3}$. En ambos casos su punto de partida son las reflexiones de Alexis de Tocqueville sobre la cuestión racial en este país, de modo que es necesario primero referirse a él para, a continuación, volver sobre los escritos de Arendt.

\footnotetext{
${ }^{1}$ ARENDT, H.; Crisis de la república, trad. G. Solana, Madrid, Taurus, 1973, pp. 96-98; Responsabilidad y juicio, trad. M. Candel, Barcelona, Paidós, 2007, p. 191; y "La ausencia de ley es inherente en los desarraigados", trad. A. Serrano de Haro, Madrid, Arbor, 742, 2010, pp. 195-196.

2 ARENDT, H.; Responsabilidad y juicio, cit., p. 191.

${ }^{3}$ ARENDT, H.; Crisis de la república, cit., pp. 96-98.
}

Alexis de Tocqueville pone de manifiesto la gravedad del problema racial en los Estados Unidos $^{4}$. El francés explica cuál es la relación entre las tres razas que habitan el territorio de este país - la india, la negra y la blanca- en el décimo capítulo del primer libro de $L a$ democracia en América. Tocqueville se refiere a los excesos de la población blanca con los indios nativos en su progresiva colonización del oeste y a las consecuencias de la sumisión de la raza negra a la esclavitud. Cuando escribe esta obra, en 1835, la esclavitud ha sido abolida en la mayoría de los Estados del Norte del país, pero para su sorpresa el resultado inmediato de la abolición no es un mayor entendimiento o una mayor igualdad entre blancos $y$ negros sino un mayor distanciamiento entre ellos. La razón es que en esas circunstancias "la desigualdad se graba en las costumbres a medida que se borra en las leyes"

Según Tocqueville las consecuencias de la esclavitud permanecen en las costumbres debido al carácter específicamente racial de la esclavitud moderna. A este respecto, las diferencias entre la esclavitud de la Antigüedad y la de la Edad Moderna son fundamentales. En el sistema esclavista de la Antigüedad el individuo que podía verse convertido en esclavo tras el curso de una guerra pertenecía a la misma raza que su

\footnotetext{
${ }^{4}$ TOCQUEVILLE, A.; La democracia en América, trad. E. Nolla, Madrid, Aguilar, 1988, I, p. 327. ARENDT, H.; Crisis de la república, cit., p. 97.

${ }^{5}$ TOCQUEVILlE, A.; La democracia en América, I, cit., p. 331.
} 
Cuadernos Electrónicos de Filosofía del Derecho

señor, de modo que no había diferencia racial entre el que ejercía el dominio y el dominado. En cambio, los modernos "han tenido cuidado de restringir [la esclavitud] a una sola de las razas humanas. Así, hicieron a la humanidad una herida menor, pero infinitamente más difícil de curar” ${ }^{\circ}$.

Tocqueville explica que, en la Antigüedad, a la manumisión le seguía un tiempo de discriminación social hacia el liberto, pero esta discriminación pronto desaparecía porque este tenía la misma apariencia física que el resto de hombres de su comunidad política. Según el francés el problema de la esclavitud moderna es que una vez desaparecida como institución jurídica permanece en la sociedad largo tiempo, porque los libertos negros no se confunden con los miembros de la sociedad blanca sino que destacan por su aspecto físico ${ }^{7}$, igual que sus descendientes. De modo que, para Tocqueville, las consecuencias de la esclavitud permanecen debido a la visibilidad de la raza negra y a las costumbres de los blancos, los "hábitos del corazón" $"$ de la sociedad que no pueden cambiarse simplemente mediante la abolición legal de esta forma de dominio. A causa de esto el francés augura la lucha entre blancos y negros en el Sur del país y considera que la relación entre

\footnotetext{
${ }^{6}$ Ibid., I, p. 328.

${ }^{7}$ Ibidem.

${ }^{8}$ Ibid., I, p. 279.
}

las dos razas es "el más temible de los males que amenazan al futuro de los Estados Unidos"9.

Según Tocqueville las buenas costumbres son más relevantes que las leyes para que un país libre conserve su libertad ${ }^{10}$. O, en otros términos, las costumbres tienen un carácter conservador más relevante que las leyes, al menos en la Edad Moderna $^{11}$; ya se orienten a conservar la libertad o, como en este caso, una relación de dominio. Por estas razones, Tocqueville considera que la única solución para remediar el problema racial es un cambio radical en las costumbres sociales mediante la mezcla entre los blancos y los negros. En otras palabras, el remedio es el mestizaje, algo que no puede ser alcanzado mediante leyes o acciones políticas. La mezcla entre blancos y negros conseguiría borrar el estigma de la raza negra y disolver la asociación entre la raza y la condición de esclavos. De modo que, a la abolición jurídica de la esclavitud es necesario que le siga la mezcla social o la abolición social completa de la esclavitud mediante el mestizaje. Lamentablemente, el mestizaje en el país le parece especialmente difícil debido al orgullo racial del hombre blanco de los Estados Unidos ${ }^{12}$.

\footnotetext{
${ }^{9}$ Ibid., I, p. 327. Su intuición es evidente, pues poco después tuvo lugar la Guerra de Secesión que supuso la división del país y que tuvo, como una de sus causas fundamentales, la disputa acerca de la cuestión racial de la esclavitud.

${ }^{10}$ Ibid., I, p. 305.

${ }^{11}$ Ibid., I, p. 328

${ }^{12}$ Ibid., I, p. 341.
} 
Con respecto al primer artículo, su

Cuadernos Electrónicos de Filosofía del Derecho

\section{La controversia sobre la educación pública} segregada en Little Rock

Transcurrido algo más de un siglo de las reflexiones de Tocqueville, Hannah Arendt comparte con este su preocupación por el racismo en los Estados Unidos. Con ocasión de este problema la autora distingue tres esferas de la existencia humana en el mundo: la esfera privada o familiar, la esfera social y la esfera política ${ }^{13}$. Arendt se aproxima al denominado "delito original" desde el punto de vista social en sus "Reflexiones sobre Little Rock" (1959) y desde el punto de vista político en "Desobediencia civil" (1970). El primer artículo se ocupa de la desaparición de la educación segregada en las escuelas públicas de los Estados Unidos. Es decir, se relaciona con la educación, un asunto que pertenece fundamentalmente a la esfera familiar y social. El segundo artículo, como indica su título, se refiere a los fenómenos de desobediencia civil que tienen lugar en el país a finales de la década de 1960. Es decir, trata de un asunto perteneciente a la esfera política.

13 ARENDT, H.; "Reflexiones sobre Little Rock", en Responsabilidad y juicio, cit., pp. 195-199. La interpretación de lo que son estas tres esferas varía en las distintas obras de Arendt, especialmente por lo que respecta a la esfera social. Por esta razón, hay que precisar que las reflexiones sobre la esfera social que se harán a continuación, que podíamos definir como positivas (pues suponen una defensa de la autonomía de esta esfera ante el Estado), hay que considerarlas casi exclusivamente como propias del artículo "Reflexiones sobre Little Rock". comprensión exige situarlo en su contexto histórico concreto. A finales de la década de 1950 los niños negros y los niños blancos estudiaban por primera vez juntos en las escuelas públicas del Sur de los Estados Unidos. La situación en la capital de Arkansas (Little Rock) fue especialmente tensa a la hora de poner en marcha la educación integrada.

La decisión judicial que había cambiado la situación en las escuelas era la sentencia Brown v. Board of Education of Topeka de 1955. Esta fue una de las sentencias más importantes de la Supreme Court sobre el problema racial porque prohibió la segregación por razas en las escuelas públicas, y esto supuso acabar con esa práctica discriminatoria que había sido la norma en los Estados del Sur hasta aquel momento. El fundamento jurídico para prohibir la segregación fue su inconstitucionalidad: el tribunal consideraba que la segregación contravenía la XIV enmienda que proclama la igual protección de las leyes para todas las personas nacidas o naturalizadas en los Estados Unidos ${ }^{14}$.

Esta decisión judicial encontró resistencia social y política en los Estados del Sur, especialmente en Arkansas. Dicha resistencia se puso de manifiesto, en primer lugar, en el retraso intencionado en la implantación de la educación

${ }^{14}$ Brown v. Board of Education of Topeka, 349 U.S. 294, 75 S. Ct. 753, 99 L. Ed. 1083 (1955). 


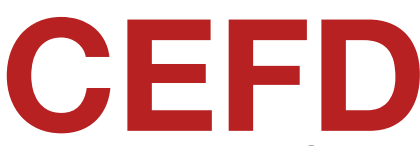

Cuadernos Electrónicos de Filosofía del Derecho

pública integrada $\mathrm{y}$, en segundo lugar, en la introducción de una enmienda en la Constitución de Arkansas para garantizar la continuidad de la segregación en el Estado. El conflicto entre el Alto Tribunal y el Estado de Arkansas hizo que, en la capital del Estado (Little Rock), los alumnos de ambas razas sufrieran la tensión de encontrarse en medio del conflicto entre la federación y el Estado $^{15}$.

La controversia jurídica terminó cuando la Supreme Court dictó la sentencia Cooper $v$. Aaron en 1958. En ella el tribunal subrayaba que la decisión de Brown v. Board of Education of Topeka había sido correcta. La corte señaló que la sumisión a dicha sentencia era un mandato constitucional y el modo de lograr el ideal de una igual justicia ante la ley para todos los ciudadanos ${ }^{16}$.

A raíz de estos acontecimientos la revista Commentary encargó a Arendt un artículo que llevó por título "Reflexiones sobre Little Rock". La revista lo consideró tan provocador que no se atrevió a publicarlo, de modo que finalmente lo sacó a la luz la revista Dissent ${ }^{17}$. La razón de la

${ }^{15}$ HARTMAN, G.; MERSKY, R. M.; y TATE, C. L.; Landmark Supreme Court Cases, Nueva York, Checkmark Books, 2007, pp. 34-39 y pp. 48-49.

${ }^{16}$ Cooper v. Aaron, 358 U.S. 1, 78 S. Ct. 1401, 3 L. Ed. 2d 5 (1958)

${ }^{17}$ Los editores de Commentary consideraron tan incorrecto el artículo de Arendt que encargaron una réplica a Sidney Hook. Sin embargo, no se decidieron a publicarlo ni siquiera acompañado de la réplica. YOUNG-BRUEHL, E.; Hannah Arendt. Una biografia, trad. M. Lloris Valdés, Barcelona, Paidós, 2006, p. 398. controversia tenía que ver, por un lado, con la aparente carencia de sensibilidad de Arendt hacia el racismo que sufrían los negros, como se ha subrayado $^{18}$. Por otro lado, tenía que ver con las consecuencias del presupuesto teórico del que partía, que se puede resumir así: la esfera social no es política ${ }^{19}$.

Para Arendt el ámbito social es aquella esfera de la vida humana que se encuentra entre la vida privada y el espacio público. Así, pertenecen a esta esfera el trabajo o la elección del cónyuge. En esta esfera, a juicio de Arendt, rige la discriminación. Así, por ejemplo, la existencia de hoteles en el lugar de vacaciones que solo aceptan miembros de una raza es perfectamente admisible, pues se trata de lugares de reunión o asociación social, es decir, donde rige la discriminación en el sentido de que uno decide con quien relacionarse. En cambio, la autora no acepta que uno sea privado del derecho a sentarse donde le plazca en un autobús, pues en este caso no cabe discriminación social. Arendt señala que esta situación no pertenece al ámbito político, pero sí al espacio público y, por ello, debe regirse por la igualdad y no por la discriminación propia del ámbito social ${ }^{20}$.

\footnotetext{
18 GINES, K. T.; Hannah Arendt and the Negro Question, Bloomington, Indiana University Press, 2014, pp. 123-130.

19 ARENDT, H.; Responsabilidad y juicio, cit., p. 196. Lo social puede introducirse de hecho en la política o la política inmiscuirse en la esfera social, pero Arendt considera que esto no debe ocurrir.

${ }^{20}$ Ibid., pp. 197-198.
} 
Según Arendt la educación pertenece fundamentalmente al ámbito familiar y al ámbito social. Al ámbito familiar en la medida en que los hijos son educados dentro de la idiosincrasia de una determinada familia y, al ámbito social, en la medida en que las escuelas son para los niños como el trabajo para los adultos, pues pertenecen a una esfera distinta a la privada y a la política ${ }^{21}$. Según Arendt el derecho de los padres a educar a sus hijos como deseen tiene como único límite político el interés legítimo del Estado en la formación de los futuros ciudadanos ${ }^{22}$.

En coherencia con su distinción entre esferas Arendt considera que ni los Estados del Sur debían imponer legalmente la educación segregada por razas, ni la Supreme Court debía imponer la educación integrada. La decisión de en compañía de quien han de estudiar los hijos pertenece a los padres, no a las instituciones. O, en otros términos, las instituciones y las leyes no han de adoptar los prejuicios de la sociedad —como habían hecho hasta aquel momento los Estados del Sur mediante las escuelas segregadas-, ni tampoco suprimir la discriminación social —como pretendía la Supreme Court con las decisiones arriba mencionadas - En resumen, la autora considera

\footnotetext{
${ }^{21}$ Ibid., pp. 201-202.

${ }^{22}$ Ibidem.
}

que la discriminación social no debe ni imponerse ni prohibirse legalmente ${ }^{23}$.

A su juicio, cuando la legislación ni impone, ni prohíbe, el problema racial deviene estrictamente social y es decisión de los padres si quieren educar a sus hijos en escuelas públicas integradas o en escuelas segregadas. Así, la consecuencia práctica del juicio de Arendt es que el Estado debía garantizar la existencia de dos tipos de escuelas públicas: unas separadas por razas y otras integradas ${ }^{24}$.

Lo anterior significa que, según Arendt, la Supreme Court hizo bien al prohibir las leyes que obligaban a segregar por razas en las escuelas porque efectivamente esta legislación infringía la igualdad ante la ley. Pero la autora no está completamente de acuerdo con el tribunal, considera que este se excedió al exigir a los padres educar a sus hijos en escuelas públicas integradas por alumnos blancos y negros con independencia de su consentimiento ${ }^{25}$. Según ella

${ }^{23}$ Ibid., p. 199. La autora, K. T. Gines, critica la visión de Arendt del racismo blanco frente a los negros en los Estados Unidos, al considerarlo un problema estrictamente social, propio de las variadas preferencias personales admisibles en el ámbito social y no un problema político en el que se exige la igualdad de todos ante la ley. Gines considera que, al tratar el racismo frente a los negros como un problema social, Arendt no propone un remedio análogo a la toma de acción que proponía para los judíos frente al antisemitismo. GINES, K. T.; Hannah Arendt and the Negro Question, cit., p. 123.

${ }^{24} \mathrm{La}$ autora no lo dice expresamente pero es la única manera de conseguir lo que ella propone, que es que los padres puedan elegir entre una educación segregada o integrada para sus hijos. Y han de ser escuelas públicas porque la educación privada no pueden permitírsela todos. ARENDT, H.; Responsabilidad y juicio, cit., p. 201.

${ }^{25}$ Ibid., pp. 187-188. 
Cuadernos Electrónicos de Filosofía del Derecho

esta decisión pertenece a los padres porque la educación de los hijos en la escuela pertenece al ámbito de lo social en el cual ni las leyes ni los jueces deben entrometerse, pues no rige la igualdad sino la discriminación, la libertad para decidir con quien relacionarse y con quien $n^{26}$.

Además, Arendt apunta que podría lograrse una mayor integración social en la educación por medios más adecuados. Indica que una posibilidad sería crear asociaciones de padres y madres para promover la integración; como un grupo de padres de ambas razas que impulsaran una escuela con alumnos blancos y negros. Esta solución tiene la ventaja de que respeta la libertad de los padres para decidir cómo educar a sus hijos $\mathrm{y}$, por tanto, no genera un conflicto entre la educación en el hogar y en la escuela ${ }^{27}$. Sin embargo, la formación de una asociación así no acaba de convencerle pues el entendimiento entre razas ha de ser un logro exclusivo de los adultos y considera que se instrumentaliza a los niños al buscarlo a través de la escuela ${ }^{28}$. Así, en "Reflexiones sobre Little Rock" no hay una respuesta o solución clara, Arendt no apunta un posible remedio para la segregación social que persiste una vez prohibida la segregación legal forzosa. La razón de esta ausencia, en el fondo, es que para ella la discriminación social no es un

\footnotetext{
${ }^{26}$ Ibid., pp. 199-201.

${ }^{27}$ Ibid., pp. 188-189.

${ }^{28}$ Ibidem.
}

problema sino una característica de esta esfera de la vida humana. Basta que las leyes garanticen la igualdad en el ámbito público, pero no la deben imponer en el ámbito social, porque "no es la discriminación y la segregación sociales, en cualquiera de sus formas, sino la legislación racial lo que constituye la perpetuación del delito original en la historia de este país" ${ }^{29}$.

\section{La exclusión constitucional de la población} negra de la ciudadanía y sus consecuencias

Transcurrida más de una década desde los acontecimientos de la ciudad de Little Rock Arendt escribe "Desobediencia civil"30. El artículo es fruto de un seminario organizado en 1970 bajo el título “¿Ha muerto la ley?” que tuvo lugar en un contexto de inquietud ante el aumento de la delincuencia y los movimientos de desobediencia civil en los Estados Unidos. Conforme a la distinción de esferas mencionada el tema del artículo pertenece a la esfera política, no a la esfera social. En él, Arendt considera que debe reconocerse el derecho de los ciudadanos a asociarse politicamente para oponerse a leyes o políticas gubernamentales con las que están en desacuerdo. Según ella, este derecho a disentir, lejos de ser contrario a la Constitución, es

\footnotetext{
${ }^{29}$ Ibid., p. 190. Se sigue esta traducción con algunos cambios.

${ }^{30}$ ARENDT, H.; "Desobediencia civil", en Crisis de la república, cit., pp. 59-108.
} 
Estas consideraciones suponen un cambio

Cuadernos Electrónicos

de Filosofía del Derecho

constitucional. En la medida en que los ciudadanos actúan pacíficamente y comprometidos por el ámbito público ponen de manifiesto de manera tácita que han aceptado la autoridad de la Constitución y, con ello, las reglas de juego de la política, fundamentalmente, el diálogo y la no-violencia. Estos ciudadanos son los desobedientes civiles que disienten de lo coyuntural, como leyes concretas y políticas del gobierno, pero están comprometidos con lo permanente, que es la Constitución y el régimen republicano ${ }^{31}$.

Según Arendt en el ámbito político la igualdad ante la ley es fundamental para que se pueda actuar $^{32}$, pero dicha igualdad no existe en los Estados Unidos en relación con la población negra. La aceptación tácita de la Constitución supone un problema cuando se refiere a la población negra. La raíz del problema es la misma Constitución de 1787, el que fuera el mayor logro del país ${ }^{33}$. La autora considera ahora que el delito original no es la esclavitud, ni su perpetuación procede de la legislación racial como apuntaba años atrás. El delito original es la exclusión de la población negra del consenso original que dio fruto a la Constitución de los Estados Unidos ${ }^{34}$.

\footnotetext{
${ }^{31}$ Ibid., pp. 83 y ss.

${ }^{32}$ Ibid., pp. 97-99.

${ }^{33}$ ARENDT, H.; Sobre la revolución, cit., p 330.

${ }^{34}$ ARENDT, H.; Crisis de la república, cit., p. 98.
}

en su perspectiva del problema, pues antes, en "Reflexiones sobre Little Rock", no era visto desde el punto de vista político-constitucional sino desde el punto de vista social y legal. La perpetuación del delito original estaba causada por las leyes raciales que imponían los prejuicios raciales mediante la segregación racial. En cambio, en "Desobediencia civil" señala que lo que perpetúa el problema racial es la misma vigencia de la Constitución porque "no había nada en la Constitución o en la intención de quienes la elaboraron cuya interpretación permitiera la inclusión del pueblo esclavo en el convenio original" 35 .

Así, el problema quedó enquistado debido a la exclusión de los negros del pacto constitucional y no debido a las costumbres xenófobas de una sociedad en la que la esclavitud había sido legal largo tiempo. Esa exclusión original, que no fue expresa sino tácita, es la causa de que el problema racial siguiera presente cuando escribe en la década de $1970^{36}$. La razón

\footnotetext{
${ }^{35}$ Ibid., p. 97.

${ }^{36}$ A pesar del tiempo transcurrido este problema no ha perdido actualidad, al menos en algunas zonas de los Estados Unidos. La muerte de Michael Brown en Ferguson, un chico negro a manos de un policía blanco en agosto de 2014, y las protestas desencadenadas a partir de entonces, ponen de manifiesto que el problema racial no está resuelto. La ciudad de Ferguson muestra de modo paradigmático la división entre las instituciones formadas por blancos y la población mayoritariamente negra. http://internacional.elpais.com/internacional/2014/08/15/actualidad /1408054824 163798.html [consultado: 9/6/16]. http://www.nytimes.com/2015/04/13/opinion/charles-blow-walterscott-is-not-on-trial.html? $\mathrm{r}=0$ [consultado: 9/6/16].
} 


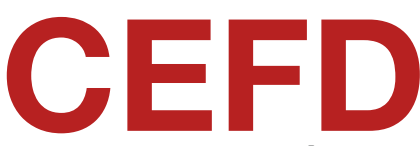

Cuadernos Electrónicos de Filosofía del Derecho

de la permanencia de un problema tan remoto, a pesar de que se trata de una exclusión tácita y no expresa de la Constitución, se explica por el carácter conservador del Derecho $^{37}$ y por la importancia atribuida en el país a aquello que procede del origen, del momento fundacional ${ }^{38}$.

Según Arendt, el delito original tiene origen y se perpetúa debido a la Constitución, por lo que es un problema jurídico. Para ella, la deliberación y la acción políticas son perecederas, se desvanecen tan pronto como deja de dialogarse o de actuar. Por eso, en el ámbito de los asuntos humanos el Derecho tiene la función de dar permanencia a dichas palabras $y$ acciones políticas $^{39}$. En esta medida el delito original es un problema de origen político: la exclusión de los negros y los indios de la deliberación constitucional, de las asambleas constituyentes y de la decisión del pueblo que tuvo como resultado la Constitución. Ahora bien, solo cuando dicha exclusión tomó forma de manera tácita en el texto constitucional, este problema se hizo duradero. Es decir, cuando esa exclusión de carácter político se materializó en Derecho y, además, en un Derecho especialmente llamado a durar: una Constitución ${ }^{40}$.

\footnotetext{
${ }^{37}$ ARENDT, H.; Crisis de la república, cit., pp. 86-87.

${ }^{38}$ ARENDT, H.; Sobre la revolución, cit., p. 280.

39 ARENDT, H.; La condición humana, trad. R. Gil Novales, Barcelona, Paidós, 1993, pp. 78 y ss.; y Sobre la revolución, cit., pp. 188-245.

${ }^{40}$ ARENDT, H.; Crisis de la república, cit., pp. 96-98.
}

Al carácter conservador del Derecho se une el carácter sagrado de la fundación en el espíritu público estadounidense. Este es un rasgo del espíritu público romano que, según Arendt, reaparece en la fundación de los Estados Unidos $^{41}$. Según este espíritu la fundación tiene “carácter sacro [...] en el sentido de que una vez que algo se ha fundado conserva su validez para todas las generaciones futuras" ${ }^{\text {"42 }}$. Esta conservación, que deriva directamente del acto fundacional, es positiva porque logra dar estabilidad a las acciones de los fundadores y constituir un régimen libre de forma duradera ${ }^{43}$.

Ahora bien, esta conservación también afecta a lo negativo. Los ciudadanos no heredan solamente las ventajas y los beneficios de una tradición política y de una Constitución, sino también las deudas o la responsabilidad por los errores cometidos. Así, según Arendt, en una comunidad política "cada generación, por el hecho de haber nacido dentro de un continuo histórico, debe cargar con los pecados de los padres en la misma medida en que se beneficia de las actuaciones de sus antecesores",44.

Lo anterior explica sucintamente por qué las consecuencias del delito original todavía

\footnotetext{
${ }^{41}$ ARENDT, H.; Sobre la revolución, cit., p. 292.

42 ARENDT, H.; Entre el pasado y el futuro. Ocho ejercicios sobre la reflexión política, trad. A. Poljak, Barcelona, Península, 1996, p. 131.

43 ARENDT, H.; Crisis de la república, cit., p. 96; y Sobre la revolución, cit., pp. 188-245.

${ }^{44}$ ARENDT, H.; Responsabilidad y juicio, cit., p. 57.
} 
Cuadernos Electrónicos de Filosofía del Derecho

perviven. Con respecto a su gravedad e importancia, esta reside en que supone privar a la población negra e indígena del derecho humano más importante para Arendt, que es condición de los demás derechos: el derecho a gozar de una ciudadanía. En otras palabras, lo que ella denomina el "derecho a tener derechos"

\section{La aceptación de la Constitución como} condición para la ciudadanía y como reglas de juego en el ámbito público

El derecho a tener derechos está garantizado cuando basta la aceptación del Derecho para entrar a formar parte de una comunidad política, de modo que, potencialmente cualquier persona puede formar parte de ella ${ }^{46}$. Al referirse al modo en que se sostiene la república estadounidense y, al mismo tiempo, se obtiene la ciudadanía, la autora sigue nuevamente a Tocqueville. Este señala que "la república existe en América [...] por un acuerdo tácito, una especie de consensus universalis" ${ }^{\prime 4}$. Arendt interpreta este consensus universalis como el asentimiento generalizado a la Constitución por parte de la ciudadanía. Esta aceptación de la Constitución es

\footnotetext{
45 ARENDT, H.; Los orígenes del totalitarismo, trad. G. Solana, Madrid, Alianza, 2006, $5^{\text {a }}$ reimpr. 2011, p. 420.

46 ARENDT, H.; "La ausencia de ley es inherente en los desarraigados", cit., p. 195.

${ }^{47}$ TOCQUEVILLE, A.; La democracia en América, cit., I, p. 377.
}

lo que sostiene la república porque de esta forma los estadounidenses entran a formar parte voluntariamente del país. Para ella los Estados Unidos es una república $\mathrm{y}$, con este término no designa solo su forma de gobierno sino también un modo concreto de pertenencia a la comunidad. Se es ciudadano de la república porque se ha aceptado su Derecho —o, más exactamente: su Constitución-, de modo que la pertenencia no atiende a criterios étnicos o lingüísticos como en los Estados nacionales ${ }^{48}$.

Al tratarse de un país formado por inmigrantes y carente de una identidad nacional única, dicha aceptación está abierta a individuos de cualquier nacionalidad: el país se sostiene "independientemente de la existencia o no de una población homogénea"49. Con razón se ha dicho que, para Arendt, solo una sociedad abierta que no toma en cuenta la nacionalidad de los nacidos en su territorio, ni de los inmigrantes adultos que llegan al país, puede garantizar el derecho a tener derechos $^{50}$.

Según lo anterior tanto el nacido en suelo estadounidense como el inmigrante son

48 ARENDT, H.; "Estado nacional y democracia", trad. J. A. Zamora, Madrid, Arbor, 742, pp. 191-194.

${ }^{49}$ ARENDT, H.; Responsabilidad y juicio, cit., p. 191.

50 P. Hayden afirma que "para garantizar el derecho a tener derechos debemos empezar a distinguir la ciudadanía de la nacionalidad y rearticular el Estado como una institución de la legalidad en vez de la soberanía. En la construcción del Estado como una "sociedad abierta", Arendt señala: "el Estado sólo conoce ciudadanos no importa de qué nacionalidad; su orden legal está abierto para todos los que viven en su territorio"'. HAYDEN, P.; Political Evil in a Global Age, Nueva York, Routledge, 2009, p. 91. 


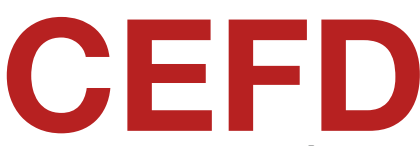

Cuadernos Electrónicos de Filosofía del Derecho

reconocidos como ciudadanos en la medida en que aceptan la Constitución. Ahora bien, los negros y los indios no eran inmigrantes llegados tras la constitución del país, sino una población que ya residía en el territorio de los Estados Unidos en el momento del pacto constitucional y que fue intencionadamente excluida del mismo. Esta población no solo fue excluida de la mencionada deliberación política fundacional, sino de la pertenencia posterior a la república. O, lo que es lo mismo, se les excluyó de la posibilidad de aceptar la Constitución, que es la forma específica de obtener la ciudadanía en este país. Así, la autora escribe que, respecto a los negros y a los indios, hay una "exclusión tácita del asentimiento tácito"51 porque estos "jamás fueron incluidos en el consensus universalis original de la República americana"52. Es decir, como no fueron incluidos expresamente en el consenso inicial se les considera tácitamente excluidos $\mathrm{y}$, por eso, no pueden aceptar la autoridad de la Constitución. Así, de acuerdo con Arendt, a consecuencia de esta exclusión tácita de la comunidad política los negros no pueden aceptar la Constitución y entrar a formar parte del país $^{53}$.

Como se ha dicho, la aceptación de la Constitución es la condición para ser ciudadano y

\footnotetext{
${ }^{51}$ ARENDT, H.; Crisis de la república, cit., p. 98.

${ }^{52}$ Ibid., p. 97.

${ }^{53}$ Ibidem.
}

también para actuar políticamente, según $\mathrm{Arendt}^{54}$. A su juicio, en el caso estadounidense dicha aceptación permite incluso el asociacionismo propio de los desobedientes civiles. De este modo, la autora caracteriza el Derecho como eminentemente directivo, no imperativo $^{55}$. El Derecho no es primariamente un mandato imperativo del poder cuyo cumplimiento se hace posible debido a la coacción, sino algo aceptado libremente aunque sea de manera tácita. Así, el reconocimiento del Derecho es como la aceptación de "las reglas del juego" que "dirigen la comunicación humana" ${ }^{\text {" }}$. Negar estas normas no significa mera desobediencia sino la negativa a entrar en la comunidad humana. El problema en el asunto que nos ocupa es que la aceptación del Derecho no es posible para la población negra excluida, según la autora ${ }^{58}$. Esto hace que el Derecho tenga un carácter imperativo o coactivo y no directivo para el excluido o no reconocido por la comunidad política ${ }^{59}$.

\footnotetext{
${ }^{54}$ Ibidem. Esta afirmación es verdadera con respecto al tema aquí tratado, pero no lo es en toda la obra de Arendt. La acción política puede situarse completamente fuera de las instituciones. ARENDT, H.; Entre el pasado y el futuro..., cit., p. 11.

${ }_{55}$ En los ensayos recogidos en Crisis de la república Arendt destaca el carácter directivo o promotor del Derecho en contraste con el énfasis en su carácter imperativo, de límite o conjunto de prohibiciones en la década de 1950. ARENDT, H.; Crisis de la república, cit., p. 195; Los orígenes del totalitarismo, cit., p. 625; y La condición humana, cit., p. 71.

${ }_{56}^{56}$ ARENDT, H.; Crisis de la república, cit., p. 195.

${ }^{57}$ Ibidem.

${ }_{58}^{58}$ Ibid. pp. 98-99.

59 SERRANO GÓMEZ, E.; Consenso y conflicto. Schmitt y Arendt: la definición de lo político, Universidad de Antioquía, 2002, p. 127.
} 


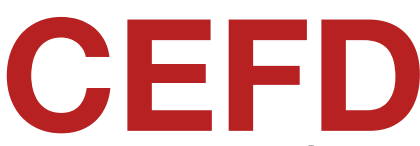

Cuadernos Electrónicos de Filosofía del Derecho

Según Arendt, la ausencia de reconocimiento constitucional de la población negra en la Constitución abocaba a la violencia a los grupos de negros rebeldes que proliferaban en la década de 1960 en los Estados Unidos. Al estar excluidos originalmente de la comunidad no podían aceptar la Constitución y, por tanto, tampoco optar por actuar políticamente, pues solo podían actuar como anarquistas contrarios a las instituciones. A consecuencia de esto la desobediencia civil pública y pacífica no era una opción para los negros porque no eran simplemente contrarios a leyes o políticas coyunturales sino que se hallaban en "abierta rebelión"60 contra las instituciones mismas de las que se encontraban excluidos ${ }^{61}$.

Estas últimas consideraciones acerca de los movimientos políticos de la población negra y la consideración global de los mismos como grupos violentos parecen particularmente injustas y quizá alejadas de la realidad. Arendt no se refiere, por ejemplo, a la marcha negra por el trabajo y la libertad de 1963. Esta marcha se desarrolló pacíficamente y concluyó con el famoso discurso de Martin Luther King. El acto no solo respetó escrupulosamente las reglas de la no violencia sino que, además, tuvo frutos políticos inmediatos como la Civil Rights Act

\footnotetext{
${ }^{60}$ ARENDT, H.; Crisis de la república, cit., pp. 98-99.

${ }^{61}$ Ibidem.
}

(Ley de los derechos civiles) en 1964, aprobada por el gobierno de J. F. Kennedy ${ }^{62}$.

Con respecto al remedio a la exclusión tácita constitucional, la autora considera que los intentos de solución al problema racial con la aprobación de las enmiendas XIV y XV fueron inútiles $^{63}$. E incluso, la Supreme Court, como autoridad dedicada a interpretar la Constitución, confirmó la exclusión con su sentencia Dred Scott v. Sandford de 1857 al afirmar que "los negros no son ni pueden ser ciudadanos en el significado de la Constitución federal"64. Así, como se ve, hasta la forma republicana de los Estados Unidos, que para la autora es el régimen político más incluyente, limita a una parte de su población el derecho a la ciudadanía. La sugerencia de Arendt para remediar el problema de la exclusión original es la propuesta, por parte del Congreso, de una enmienda constitucional "dirigida expresamente a la población negra de América" ${ }^{\natural 5}$.

\footnotetext{
${ }^{62}$ Para una crítica a la ausencia de Martin Luther King en Arendt véase FIRE HINZE, Ch.; "Reconsidering Little Rock: Hannah Arendt, Martin Luther King Jr., and Catholic Social Thought on Children and Families in the Struggle for Justice", Washington, Journal of the Society of Christian Ethics, 29, 1, 2009, p. 32. También GINES, K. T.; Hannah Arendt and the Negro Question, cit., p. 122.

${ }^{63}$ ARENDT, H.; Crisis de la república, cit., p. 98. Las enmiendas XIV y XV son del año 1868 y 1870 respectivamente. La XIV señala que "todas las personas naturalizadas en Estados Unidos [...] son ciudadanas de Estados Unidos" y la XV señala que "el derecho de los ciudadanos de Estados Unidos a votar no puede ser denegado [...] de acuerdo con la raza, el color o la condición previa de esclavitud".

${ }^{64}$ Dred Scott v. Sandford, 60 U.S. 393, 15 L. Ed. 691 (1857). Citada en ARENDT, H.; Crisis de la república, cit., p. 99.

${ }^{65}$ ARENDT, H.; Crisis de la república, cit., p. 99.
} 
Cuadernos Electrónicos de Filosofía del Derecho

\section{Conclusiones}

Según se ha dicho, tan impertinente es la discriminación en el ámbito político como la igualdad en el ámbito social. Así, para Arendt, la igualdad es propia de la esfera política y la discriminación lo es de la esfera social.

Esta división otorga la clave para comprender el modelo republicano estadounidense tal y como lo entiende Arendt. La igualdad política entendida como la admisión de cualquier individuo como ciudadano de la república $\mathrm{o}$, en otros términos, la garantía del derecho a tener derechos para cualquier individuo, solo es posible en la medida en que hay una verdadera igualdad de acceso a la ciudadanía.

De este modo, la lengua, la raza, la cultura y la nacionalidad de origen del individuo permanecen en su esfera social, de modo que ninguna de ellas, en cualquiera de sus formas, constituye un requisito para su pertenencia a la comunidad política. Todos estos elementos de su identidad no serían políticos en sentido estricto, sino pertenecientes a la esfera social.

El delito original, es decir, la exclusión de la población negra estadounidense del pacto constitucional de los Estados Unidos supone una intromisión de un aspecto que debía permanecer en la esfera social, como es la raza, en el ámbito político. Esto contradice, para Arendt, el espíritu republicano del país en su mismo origen, pues este espíritu supone que el país acoge a cualquiera como ciudadano desde el momento en que acepta tácitamente la Constitución.

En su tratamiento del racismo hacia la población negra es llamativo que la autora no invite a este colectivo a actuar políticamente, algo en que insistía cuando los colectivos políticamente discriminados eran otros, como el pueblo judío durante la Segunda Guerra Mundial. Lo que impide a la autora invitar a la población negra a entrar en acción es precisamente su propia lectura de la exclusión de este pueblo del pacto constitucional estadounidense, pues esta exclusión tiene como consecuencia la imposibilidad de aceptar la Constitución y, en consecuencia, la imposibilidad de actuar políticamente como ciudadanos.

Por otro lado, el modelo republicano arendtiano (basado en buena medida en los Estados Unidos) es atractivo, pues permite, en principio, la inclusión de cualquier individuo en la comunidad política, siempre que asienta a la Constitución del país. Al mismo tiempo se mantiene una considerable libertad en el ámbito social. Ahora bien, esto no carece de problemas, pues la política puede quedar privada, en parte, de su contenido, a un tiempo que la esfera social se separa, quizá en exceso, de la esfera política y de 


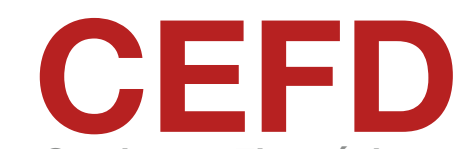

Cuadernos Electrónicos

de Filosofía del Derecho

la búsqueda del bien común, que siempre requiere

un grado de coordinación. 
Cuadernos Electrónicos de Filosofía del Derecho

\section{Bibliografía}

ARENDT, H.; Crisis de la república, trad. G. Solana, Madrid, Taurus, 1973, 234 pp.

ARENDT, H.; La condición humana, trad. R. Gil Novales, Barcelona, Paidós, 1993, 366 pp.

ARENDT, H.; Entre el pasado y el futuro. Ocho ejercicios sobre la reflexión política, trad. A. Poljak, Barcelona, Península, 1996, 315 pp.

ARENDT, H.; Los orígenes del totalitarismo, trad. G. Solana, Madrid, Alianza, 2006, $5^{\text {a }}$ reimpr., 2011, 695 pp.

ARENDT, H.; Responsabilidad y juicio, trad. M. Candel, Barcelona, Paidós, 2007, 273 pp.

ARENDT, H.; Sobre la revolución, trad. P. Bravo, Madrid, Alianza, 1998, 2 ${ }^{\mathrm{a}}$ reempr. 2009, 398 pp.

ARENDT, H.; "La ausencia de ley es inherente en los desarraigados", trad. A. Serrano de Haro, Madrid, Arbor, 742, 2010, pp. 195-196.

ARENDT, H.; "Estado nacional y democracia", trad. J. A. Zamora, Madrid, Arbor, 742, 2010, pp. 191-194.

FIRE HINZE, Ch.; "Reconsidering Little Rock: Hannah Arendt, Martin Luther King Jr., and Catholic Social Thought on Children and Families in the Struggle for Justice", Washington, Journal of the Society of Christian Ethics, 29, 1, 2009, pp. 25-50.

GINES, K. T.; Hannah Arendt and the Negro Question, Bloomington, Indiana University Press, 2014, 174 pp.

HARTMAN, G.; MERSKY, R. M.; y TATE, C. L., Landmark Supreme Court Cases, Nueva York, Checkmark Books, 2007, 594 pp.

HAYDEN, P.; Political Evil in a Global Age. Hannah Arendt and International Theory, Nueva York, Routledge, 2009, 160 pp.

SERRANO GÓMEZ, E.; Consenso y conflicto. Schmitt y Arendt: la definición de lo político, Medellín, Universidad de Antioquía, 2002, 196 pp.

TOCQUEVILLE, A.; La democracia en América (II tomos), trad. E. Nolla, Madrid, Aguilar, 1988, 440 pp., 497 pp.

YOUNG-BRUEHL, E.; Hannah Arendt. Una biografía, trad. M. Lloris Valdés, Barcelona, Paidós, 2006, 648 pp. 